\title{
Pengaruh Kompetensi Kewirausahaan Terhadap Kinerja Usaha Kedai Kopi Skala Mikro dan Kecil Pada Masa Pandemi Covid-19 di Kota Medan
}

\author{
Muhammad Reza Aulia \\ Program Studii Agribisnis, Fakultas Pertanian, Unika St. Thomas \\ Email : m.reza19.mr@gmail.com
}

\begin{abstract}
Abstrak
Tujuan dari penelitian ini adalah menganalisis pengaruh kompetensi kewirausahaan terhadap kinerja usaha kedai kopi skala mikro dan kecil. Penelitian ini dilakukan pada bulan April 2020 hingga bulan Mei 2020 di Kota Medan. Data yang digunakan diperoleh dari hasil wawancara menggunakan kuesioner. Jumlah sampel yang digunakan sebanyak 60 unit yang terdiri dari 30 unit usaha kedai kopi skala mikro dan 30 unit usaha kedai kopi skala kecil yang dipilih dengan teknik random sampling. Analisis data dilakukan menggunakan metode PLS (Partial Least Square) dengan bantuan software SMART PLS 3. Hasil penelitian menunjukkan bahwa pada situasi pandemi Covid-19 kinerja usaha tidak dipengaruhi oleh kompetensi kewirausahaan baik pada skala mikro maupun skala kecil.
\end{abstract}

Kata Kunci : Lingkungan Bisnis, Kompetensi Kewirausahaan, Kinerja Usaha, Kedai Kopi, PLS

\begin{abstract}
This research aims to analyze the influence of entrepreneurial competencies towards business performance of micro and small scale coffee shop. This research was done from April to May 2020 in Medan. This research used 60 data samples of coffee shop consist of 30 unit micro scale and 30 unit small scale that were collected through random sampling. The data were analyzed by PLS (Partial Least Square) analysis with SMART PLS 3 software. The result showed that in Covid-19 pandemic business performance were not influenced by entrepreneurial competencies both in micro scale model and small scale model.
\end{abstract}

Keywords: Business Environment, Entrepreneurial Competencies, Business Performance, Coffee Shop, Partial Least Square

\section{PENDAHULUAN}

Usaha Mikro, Kecil dan Mengenah (UMKM) merupakan sektor yang sangat penting dimana pertumbuhan UMKM setiap tahunnya mengalami peningkatan sehingga dapat menjadi kekuatan strategis untuk mempercepat pembangunan nasional. Hal ini sesuai dengan isi UU No 20 Tahun 2008 Bab 3 pasal V yang berbunyi "Meningkatkan peran UMKM dapat mempercepat pembangunan daerah, memperbanyak penciptaan lapangan kerja, pemerataan pendapatan, pertumbuhan ekonomi dan pengentasan rakyat dari kemiskinan”.

Peran UMKM dalam menggerakkan roda perekonomian nasional bukan hanya sebagai benih dari tumbuhnya bisnis besar namun juga sebagai penyedia produk maupun jasa yang tidak mampu diproduksi usaha besar karena kurang efisien dalam hal biaya. UMKM bagi negara berkembang sangat penting dalam hal perbaikan perekonomian negara (Tambunan, 2009).

Pada hari Rabu tanggal 1 April 2020, Menteri Keuangan Sri Mulyani Indrawati berkata bahwa UMKM adalah salah satu sektor yang paling tertekan akibat wabah pandemi Covid-19 yang mengalami penurunan signifikan. Kondisi pandemi Covid-19 mengharuskan masyarakat melakukan kegiatan dari rumah sehingga UMKM tidak dapat melakukan kegiatan sebagaimana mestinya, hal ini menyebabkan kewajiban memenuhi kredit terganganggu, juga berpengaruh pada semakin buruknya kondisi perekonomian. Seharusnya UMKM menjadi penyelamat ekonomi seperti pada saat krisis pada tahun 1997-1998. Namun, karena adanya pembatasan-pembatasan kegiatan sosial dan ekonomi menyebabkan UMKM tak dapat menjadi penyelamat dan megalami pukulan sangat besar. Hal ini diperkuat pendapatat Ozili (2020) yang mengatakan bahwa pembatasan-pembatasan, social distancing dan ketidakpastian situasi mengarahkan kepada krisis ekonomi global.

UMKM yang saat ini mengalami kemunduran bahkan kebangkrutan salah satunya adalah bisnis kedai kopi. Bisnis ini sangat tergantung pada kegemaran masyarakat Indonesia akan berkumpul serta kegiatan sosial lainnya. Namun, karena adanya pembatasan-pembatasan maka bisnis ini sangat terganggu dan berpengaruh pada penurunan pendapatan. Di samping maraknya UMKM yang gulung tikar, ada pula yang masih bertahan bahkan masih meraup keuntungan. Perlu ada kajian tentang faktor yang membuat bisnis bisa bertahan dalam kondisi pandemi.

Mengidentifikasi kompetensi wirausaha merupakan isu penting untuk mempercepat pengembangan kewirausahaan (Rahman et al. 2016). 
Untuk mencari tahu sesuatu yang berperan dalam membuat bisnis bertahan dalam kondisi pandemi Covid-19 maka perlu dikaji lingkungan bisnis dan kompetensi kewirausahaan. Selain itu perlu juga dikaji apakah skala usaha juga berpengaruh pada kemampuan bisnis bertahan. Menurut Bergevoet (2004) perbedaan skala usaha menyebabkan adanya perbedaan kompetensi kewirausahaan

Wilkinson (2002) menyatakan bahwa usaha mikro, kecil dan menengah akan tumbuh apabila lingkungan aturan/kebijakan mendukung, lingkungan makro ekonomi stabil dan lingkungan sosial menghargai keberhasilan usaha seseorang. Hal ini menjukkan bahwa lingkungan bisnis dan kompetensi kewirausahaan untuk meningkatkan kinerja usaha dalam upaya bertahan dalam situasi pandemi Covid-19 menjadi isu penting untuk dikaji.

Oleh sebab itu tujuan penelitian ini adalah menganalisis pengaruh lingkungan bisnis dan kompetensi kewirausahaan terhadap kinerja usaha kedai kopi skala mikro dan kecil pada masa pandemi Covid-19 di kota Medan.

\section{METODE PENELITIAN \\ Kerangka Pemikiran}

Lingkungan bisnis merupakan segala hal yang ada diluar perusahaan namun dapat menimbulkan peluang dan juga ancaman bagi perusahaan (Glueck dan Jauch, 1999). Pierces dan Robinson (2008) menggolongkan lingkungan bisnis menjadi 3 golongan yaitu

1. Lingkungan jauh yang terdiri dari faktor ekonomi, sosial, politik, teknologi, dan ekologi.

2. Lingkungan industri yang terdiri dari hambatan masuk, kekuatan pemasok, kekuatan pembeli, ketersediaan subsitusi, dan persaingan antar perusahaan.

3. Lingkungan operasional yang terdiri dari pesaing, kreditor, pelanggan, tenaga kerja dan pemasok

Faktor lingkungan bisnis seperti kebijakan pemerintah, kekuatan hukum dan politik, teknologi, sumberdaya, pesaing, selera pelanggan dan pengelolaan perusahaan memengaruhi kinerja perusahaan (Hunger dan Wheelen, 2007). Hal ini menunjukkan bahwa faktor lingkungan eksternal bisnis sangat penting dalam meningkatkan kinerja usaha (H1).

Man et al. (2002) mendefinisikan kompetensi kewirausahaan sebagai kemampuan total seorang wirausaha untuk melakukan pekerjaan dengan sukses. Sementara Lackéus (2013) mendefinisikan kompetensi kewirausahaan sebagai pengetahuan, keterampilan dan sikap yang mempengaruhi kemauan dan kemampuan untuk melakukan pekerjaan kewirausahaan untuk menciptakan nilai baru. Menurut Wickam (2004) ada 11 kompetensi kewirausahaan diantaranya strategik, perencanaan, pemasaran, pengelolaan keuangan, manajemen teknis, manajemen waktu,kepemimpinan, memotivasi orang lain, pendelegasian, komunikasi,dan negosiasi. Pada penelitian Darya (2012) menunjukkan hasil dimana kompetensi kewirausahaan dengan kinerja usaha memiliki hubungan positif. Hal ini menunjukkan bahwa kompetensi merupakan faktor yang sangat penting dalam meningkatkan kinerja usaha (H2).

Kinerja Usaha yang dimaksud dapat diartikan sebagai gambaran hasil dari pencapaian pelaksanaan kegiatan bisnis dalam mewujudkan sasaran, tujuan, visi, dan misi organisasi yang dituangkan melalui perencanaan strategis (Moeheriono 2009). Jain (2011) menggambarkan model (gambar 1) bahwa selain lingkungan bisnis memiliki hubungan kepada kinerja usaha (H1), kompetensi kewirausahaan memiliki hubungan kepada kinerja usaha (H2), lingkugan bisnis juga memiliki hubungan kepada kompetensi kewirausahaan (H3) yang didukung pernyataan Oyebanji (1994).

\section{Lokasi dan Waktu Penelitian}

Penelitian ini dilakukan di kota Medan dalam jangka waktu selama 3 bulan dari bulan April 2020 hingga Mei 2020.

\section{Jenis dan Sumber Data}

Penelitian ini menggunakan data primer dan data sekunder. Data primer diperoleh dari hasil observasi dan hasil wawancara dengan pemilik kedai kopi di lokasi penelitian dengan bantuan kuesioner. Data sekunder didapatkan Dinas Koperasi dan UMKM kota Medan.

\section{Metode Pengambilan Sampel}

Populasi dalam penelitian ini adalah seluruh wirausaha kedai kopi skala mikro dan kecil di kota Medan yang belum diketahui jumlah keseluruhannya. Untuk membedakan skala mikro dan kecil maka dapat merujuk pada Undang-undang nomor 20 tahun 2008 tentang Usaha Mikro, Kecil dan Menengah (UMKM) sebagai berikut:

1. Usaha Mikro memiliki asset maximal 50 juta Rupiah dan omset maximal 300 juta Rupiah.

2. Usaha Kecil lebih besar dari kriteria usaha mikro dengan batas maximal asset 500 juta Rupiah dan omset 2,5 miliar Rupiah.

Sampel ditentukan dengan menggunakan rumus Slovyn dan menggunakan margin of error sebesar 10 persen, maka jumlah sampel minimal yang dapat diambil sebesar 51,69. Agar hasil penelitian ini lebih baik maka sampel diambil menjadi 60 responden dengan pembagian 30 unit skala mikro dan 30 unit skala kecil dengan teknik random sampling.

\section{Variabel Penelitian}

Variabel penelitian merupakan konsep yang dapat diukur. Variabel-variabel yang akan digunakan 
dalam penelitian ini terdiri dari variabel laten dan variabel manifest sebagai indikator dari variabel laten. Untuk dapat mengukur variabel laten dibutuhkan variabel indikator. Variabel indikator atau variabel manifest merupakan variabel yang menjelaskan atau mengukur variabel laten. Lingkungan bisnis, kompetensi kewirausahaan dan kinerja usaha tidak dapat diukur secara langsung, dibutuhkan variabel lainnya yang dikenal dengan sebutan variabel indikator yang dapat menjelaskan kondisi lingkungan bisnis, kompetensi kewirausahaan dan kinerja usaha. Pada penelitian ini, Lingkungan bisnis dijelaskan oleh jaringan sosial (X1.1), kebijakan pemerintah (X1.2), ketersediaan input (X1.3). Kompetensi kewirausahaan dijelaskan oleh variabel kemampuan manajerial (Y1.1), kemampuan konseptual (Y1.2), kemampuan sosial (Y1.3), kemampuan membuat keputusan (Y1.4) dan kemampuan mengatur waktu (Y1.5). Kinerja usaha dijelaskan oleh variabel keuntungan (Y2.1) dan volume penjualan (Y2.2). Seluruh variabel indikator dukumpulkan dengan bantuan kuesioner dengan menggunakan skala likert dengan 1 sangat tidak setuju dan 5 sangat setuju yang selanjutnya dimasukkan kedalam model analisis PLS seperti pada Gambar 1.

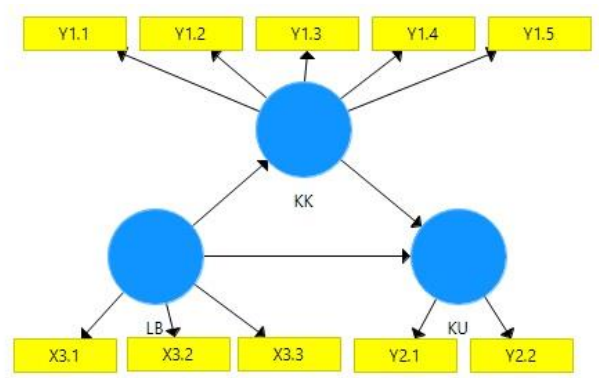

Gambar 1 Model Analisis PLS

\section{PLS (Partial Least Square)}

Partial Least Square merupakan metode analisis yang digunakan untuk menganalisis hal yang cukup kompleks yang menggabungkan regresi dengan path analysis untuk menguji hipotesis mengenai hubunganlangsung maupun tidak langsung antara variabel yang diamati dan variabellaten.

Persamaan pemodelan PLS menggambarkan semua hubungan variabel dependen dan variabel independen didalam suatu analisis . Analisis PLS dilakukan dengan bantuan program SMART PLS 3. Program ini mampu menggambarkan hubunganhubungan yang dibangun dalam model berdasarkan teori sehingga mampu menganalisis faktor-faktor yang mempengaruhi karakteristik kewirausahaan, kompetensi kewirausahaan dan kinerja usaha, serta hubungan dan pengaruhnya.

Beberapa keunggulan PLS menurut Abdillah \& Hartono (2015) diantaranya :

1. Mampu memodelkan model kompleks yang memiliki banyak variabel dependen dan independen.
2. Mampu mengelola masalah multikolinieritas antar variabel independen.

3. Hasil tetap kokoh walaupun ada data yang tidak normal dan hilang.

4. Menghasilkan variabel laten independen secara langsung berbasis cross production yang melibatkan variabel laten dependen sebagai kekuatan prediksi dan dapat digunakan pada konstruk reektif dan formatif.

5. Dapat diguakan pada sample kecil dan tidak mensyaratkan data berdistribusi normal.

6. Dapat digunakan pada data dengan tipe berskala berbeda, yaitu nominal, ordinal, dan kontinus.

Metode PLS dipilih berdasarkan pertimbangan bahwa seluruh variabel laten tidak dapat diukur secara langsung. Perlu dikaji faktor faktor yang mempengaruhi variabel laten tersebut diantaranya karakteristik individual, karakteristik psikologis, kompetensi kewirausahaan, kinerja usaha. PLS merupakan metode dengan pendekatan varian yang bersifat predictive model, sedangkan SEM yang berbasis kovarian umumnya menguji teori (Latan dan Ghozali, 2015).

Dalam PLS terdapat model pengukuran dan model struktural. Model pengukuran merupakan hubungan antara item yang diobservasi dengan variabel laten. Sedangkan model struktural penjelasan hubunngan antar variabel laten. Maka dari itu model pengukuran harus valid dan reliable sedangkan model struktural dinilai dengan mengevaluasi daya penjelas (explanatory power) dan tingkat signifikansi koefisien jalur.

Langkah langkah analisis data PLS menurut Latan dan Ghozali (2015).

1. Evaluasi Model Pengukuran (Outer Model)

Penting untuk dievaluasi apakah didalam model pengukuran variabel manifestnya (indikator) dapat mengukur variabel laten (konstruk) dengan benar. Salah satu yang dapat dilakukan adalah dengan cara menilai tingkat validitas variabel manifest berdasarkan nilai loading factor $(\lambda)$ apakah lebih besar atau lebih kecil dari 0.5. Jika nilai loading factor menunjukkan lebih besar dari 0.5 maka variabel manifest dinyatakan baik (valid) untuk mengukur variabel laten namun jika menunjukkan angka lebih kecil dari 0.5 maka variabel manifest harus dibuang karena tidak baik untuk mengukur variabel laten. Evaluasi nilai loading factor dapat dilihat pada Tabel 1 dan 2 .

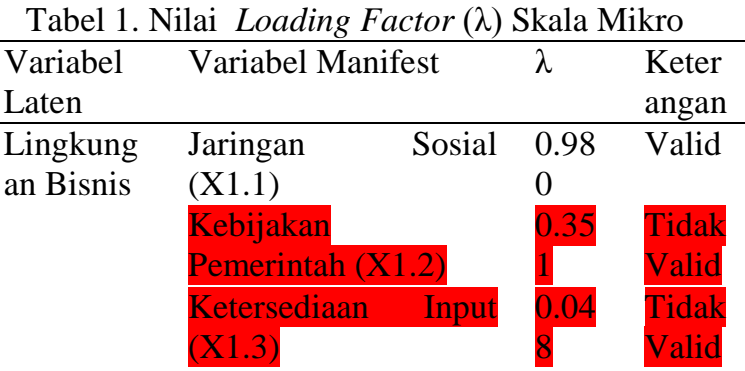


Kompeten

si

Kewiraus ahaan
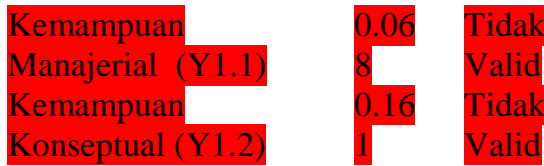

Kemampuan Sosial

0.95

Valid (Y1.3) 0
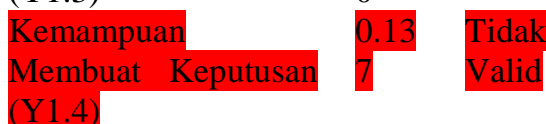

Kemampuan

0.53

Valid

Mengatur Waktu 0

(Y1.5)

Kinerja

Keuntungan

0.99
0

Volume Penjualan

0.98

6

Pada tabel 1 dapat kita lihat bahwa variabel kebijakan pemerintah (X1.2), ketersediaan input (X1.3), kemampuan manajerial (Y1.1), kemampuan konseptual (Y1.2), kemampuan membuat keputusan (Y1.4) memiliki nilai loading factor lebih kecil dari 0.5 yang berarti variabel dinyatakan tidak valid dan harus dihilangkan dalam model.

Tabel 2. Nilai Loading Factor $(\lambda)$ Skala Kecil

\begin{tabular}{llll}
\hline $\begin{array}{l}\text { Variabel } \\
\text { Laten }\end{array}$ & Variabel Manifest & $\Lambda$ & $\begin{array}{l}\text { Kete } \\
\text { rang } \\
\text { an }\end{array}$ \\
\hline Lingkung & Jaringan Sosial & 0.92 & Vali \\
an Bisnis & (X1.1) & 6 & d \\
& Kebijakan & 0.12 & Tida \\
& Pemerintah (X1.2) & 1 & k \\
& & & Vali \\
& Ketersediaan & 0.63 & Vali \\
& Input (X1.3) & 1 & $\mathrm{~d}$ \\
Kompeten & Kemampuan & 0.89 & Vali \\
si & Manajerial (Y1.1) & 7 & $\mathrm{~d}$ \\
Kewiraus & Kemampuan & 0.56 & Vali \\
ahaan & Konseptual (Y1.2) & 7 & $\mathrm{~d}$ \\
& Kemampuan & 0.92 & Vali \\
& Sosial (Y1.3) & 5 & $\mathrm{~d}$ \\
& Kemampuan & 0.64 & Vali \\
& Membuat & 6 & $\mathrm{~d}$ \\
& Keputusan (Y1.4) & & \\
Kemampuan & 0.67 & Vali \\
Kinerja & Kengatur Waktu & 4 & $\mathrm{~d}$ \\
& Keuntungan & 0.99 & Vali \\
& Volume Penjualan & 0.99 & Vali \\
& & 1 & $\mathrm{~d}$ \\
\hline
\end{tabular}

Pada Tabel 2 dapat kita lihat bahwa seluruh variabel memiliki nilai loading factor lebih dari 0.5 , kecuali kebijakan pemerintah (X1.2) yang memiliki nilai loading faktor di bawah 0.5, maka harus dihilangkan dalam model.

2. Evaluasi Model Struktural (Inner Model)
Pengujian ini dilakukan dengan melihat $\mathrm{R}$ square, Q-square, Goodnes of fit (GoF), dan Fsquare. R-square digunakan untuk menilai pengaruh variabel laten dependen apakah mempunyai pengaruh substantif (Latan dan Ghozali 2015). Qsquare digunakan untuk mengukur seberapa baik nilai observasi yang dihasilkan oleh model. Lebih lengkapnya dapat dilihat pada tabel 3.

Tabel 3. Kriteria model struktural

\begin{tabular}{llc}
\hline Kriteria & \multicolumn{1}{c}{ Rule of Thumb } & Sumber \\
\hline R-square & $0.75:$ kuat $; 0.5:$ & \\
& moderat; & Latan dan \\
& $0.35:$ lemah & Ghozali 2015 \\
Q-square & $>0$ berarti baik, & \\
& $<0$ berarti tidak & \\
& baik GoF & $0.26:$ besar, \\
& $0.13:$ medium, \\
& $0.02:$ kecil \\
F-square & $0.35:$ besar, \\
& $0.15:$ medium, \\
& $0.02:$ kecil \\
\hline
\end{tabular}

Sebaran nilai r-square dapat dilihat pada tabel 4 dimana variabel kompetensi kewirausahaan dan variabel kinerja usaha model skala mikro adalah 0,407 yang berarti moderat dan 0,813 yang berarti kuat, hal ini berarti faktor-faktor yang digunakan untuk mengukur kompetensi kewirausahaan dan kinerja usaha, mampu menjelaskan keragaman nilai kompetensi kewirausahaan dan kinerja usaha sebesar $40,7 \%$ dan $81,3 \%$, sisanya dijelaskan oleh variabel lain yang tidak ada di dalam model.

Tabel 4. Sebaran Nilai R-square

\begin{tabular}{lcc}
\hline \multirow{2}{*}{$\begin{array}{c}\text { Variabel Laten } \\
\text { Endogen }\end{array}$} & \multicolumn{2}{c}{ R-square } \\
\cline { 2 - 3 } & Skala kecil & Skala mikro \\
\hline Kompetensi & 0.769 & 0.407 \\
Kewirausahaan & & \\
Kinerja Usaha & 0.670 & 0.813 \\
\hline
\end{tabular}

Sebaran nilai R-square variabel kompetensi kewirausahaan dan variabel kinerja usaha model skala kecil adalah 0,769 yang berarti kuat dan 0,670 yang berarti moderat, hal ini berarti faktor-faktor yang digunakan untuk mengukur kompetensi kewirausahaan dan kinerja usaha, mampu menjelaskan keragaman nilai kompetensi kewirausahaan dan kinerja usaha sebesar $76,9 \%$ dan $6,7 \%$, sisanya dijelaskan oleh variabel lain yang tidak ada di dalam model.

\section{Pengujian Hipotesis (resampling boostraping)}

Dalam model PLS model yang diuji dapat menggunakan asumsi; data tidak harus berdistribusi normal; skala pengukuran boleh berupa nominal, ordindal, interval dan rasio; indikator boleh relfektif maupun formatif; dan tidak harus berdasarkan teori (Latan dan Ghozali, 2015). Pengujian hipotesis 
dinilai berdasarkan nilai t-hitung. Kriteria untuk menolak dan menerima hipotesis yang diajukan dinilai berdasarkan perbandingan nilai t-hitung dan t-tabel. Apabila nilai t-hitung lebih besar dari pada t-tabel maka hipotesis diterima. Namun apabila thitung lebih kecil dari pada t-tabel maka hipotesis ditolak. Pada penelitian ini menggunakan alpha 5 persen. Nilai t-tabel untuk aplha 5\% adalah 1,96, tidak semua hipotesis signifikan karena p-value ada yang lebih kecil dari 1,96. Hasil pengujian hipotesis dapat dilihat pada bab hasil dan pembahasan.

\section{HASIL DAN PEMBAHASAN}

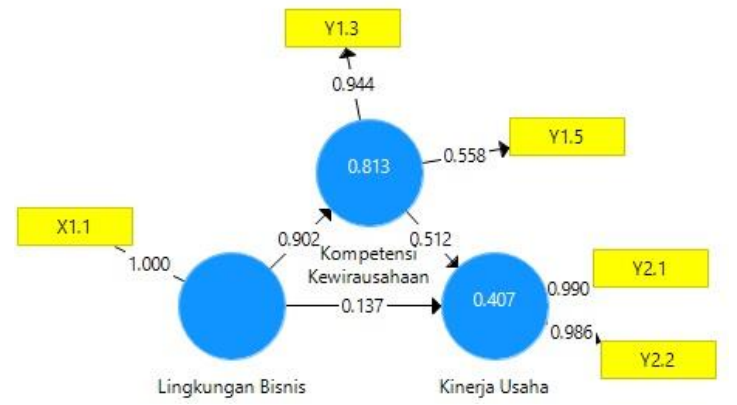

Gambar 2 Model Kedai Kopi Skala Mikro

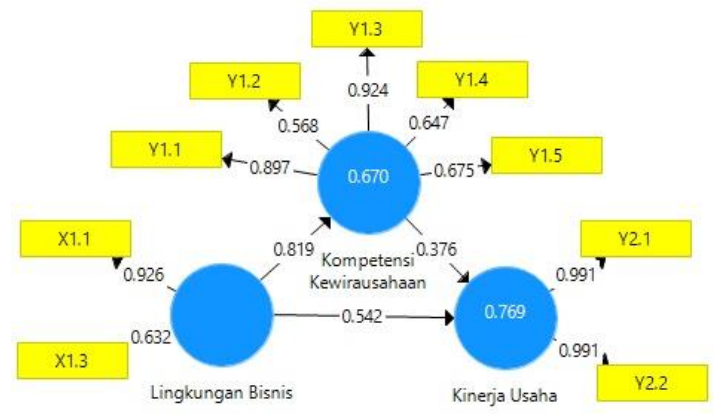

Gambar 3 Model Kedai Kopi Skala Kecil

Tabel 5. Hasil Uji Hipotesis Skala Mikro Huhubungan pengaruh t-hitung p-value Ketera

\begin{tabular}{lccl} 
& & & ngan \\
\hline Kompetensi & 1.550 & 0.122 & $\begin{array}{l}\text { Tidak } \\
\text { Kewirausahaan --> }\end{array}$ \\
Kinerja Usaha & & & $\begin{array}{l}\text { Signifi } \\
\text { kan }\end{array}$ \\
Lingkungan Bisnis --> & $25.600 *$ & $0.000 *$ & $\begin{array}{l}\text { Signifi } \\
\text { Kan }\end{array}$ \\
Kompetensi & & & \\
Kewirausahaan & & & \\
Lingkungan Bisnis --> & 0.373 & 0.709 & $\begin{array}{l}\text { Tidak } \\
\text { Kignifi } \\
\text { Kinerja Usaha }\end{array}$ \\
& & & $\begin{array}{l}\text { Sign } \\
\text { kan }\end{array}$ \\
\hline
\end{tabular}

Keterangan :

*p-value $<0,05=$

signifikan, $* \mathrm{t}(0.05)$ :

1.96

Tabel 6. Hasil Uji Hipotesis Skala Kecil

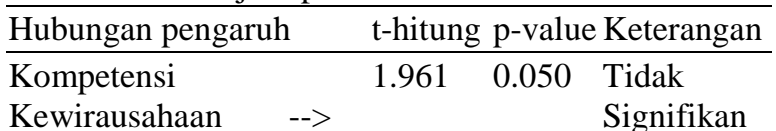

Kinerja Usaha

Lingkungan Bisnis --> $17.804 * 0.000 *$ Signifikan Kompetensi

Kewirausahaan

Lingkungan Bisnis --> $3.008 * 0.003 *$ Signifikan Kinerja Usaha

Keterangan :

*p-value $<0,05 \quad=$

signifikan, $\quad * \mathrm{t}(0.05)$ :

1.96

Dalam penelitian ini kompetensi kewirausahaan ternyata tidak berpengaruh signifikan terhadap kinerja usaha baik pada skala mikro maupun skala kecil. Hal ini tidak sesuai dengan penelitian Aliyu (2017), Tehsen dan Ramayah (2015) dan Radzi et al. (2017) dimana hasil penelitian mereka menunjukkan kompetensi kewirausahaan berpengaruh signifikan pada kinerja usaha.

Kinerja usaha kedai kopi skala mikro dan kecil tidak dipengaruhi oleh kompetensi kewirausahaan disebabkan oleh situasi pandemi Covid-19. Hal ini dibuktikan oleh penelitian Aulia (2020) yang menyatakan bahwa kompetensi kewirausahaan mendukung peningkatakan kinerja usaha pada situasi sebelum pandemi Covid-19.

Tabel 6 menunjukkan bahwa pada model skala kecil lingkungan bisnis berpengaruh signifikan terhadap kinerja usaha. Hal ini menunjukkan bahwa semakin baik lingkungan bisnis maka kinerja usaha juga akan semakin baik (H1 diterima). Namun, berbeda hal pada model skala mikro (tabel 5) yang menunjukkan bahwa lingkungan bisnis tidak berpengaruh signifikan terhadap kinerja usaha. Hal ini menunjukkan bahwa kinerja usaha kedai kopi skala mikro dalam penelitian ini dipengaruhi kuat oleh faktor lain.

Tabel 5 dan 6 menunjukkan bahwa pada model skala mikro dan skala kecil, lingkungan bisnis berpengaruh signifikan pada kompetensi kewirausahaan. Variabel indikator yang merefleksikan lingkungan bisnis pada skala mikro hanya jaringan sosial (X1.1) dengan nilai loading factor penuh yakni 1.000 (gambar 2). Hal ini dikarenkan faktor lainnya dihilangkan karena tidak memenuhi syarat nilai loading factor sebesar 0.5.

Pada skala kecil, selain jaringan social (X1.1), faktor lain yakni ketersediaan input (X1.3) juga mampu merefleksikan lingkungan bisnis dengan nilai loading factor 0.632 (gambar 3). Hal ini mengindikasikan bahwa perlu ada perbedaan perlakuan pada skala mikro dan kecil untuk meningkatkan kompetensi kewirausahaan. Pada skala mikro cukup dengan meningkatkan jaringan sosial sementara pada skala kecil perlu juga meningkatkan ketersediaan input.

Pada skala kecil ketersediaan input menjadi hal yang penting dalam merefleksikan lingkungan bisnis dimana pelaku usaha skala kecil 
menggunakan kopi yang berkualitas baik dari daerah daerah tertentu misalkan kopi gayo, wamena, toraja, bogor dan flores yang tidak selalu tersedia. Pelaku usaha yang memiliki banyak pemasok dan mampu menyimpan bahan input dalam jumlah besar berupa biji kopi ditambah memiliki mesin roasting sendiri selalu ramai dikunjungi oleh pengunjung yang mengindikasikan volume penjualan yang stabil, selain itu juga mendukung kompetensi kewirausahaan seorang wirusaha dalam menjalankan usahanya. Berbeda pada pelaku usaha yang tergantung pada satu pemasok, membeli biji kopi dari kedai kopi lain dan tidak mampu menyimpan biji kopi dalam jumlah besar maka volume penjualan tidak stabil dikarenakan pengunjung yang datang juga tidak stabil, selain itu kompetensi kewirusahaan juga dinilai kurang baik khususnya kemampuan manajerial.

\section{KESIMPULAN}

Kompetensi kewirausahaan kedai kopi skala mikro dan skala kecil dipengaruhi secara signifikan oleh lingkungan bisnis. Sedangkan kinerja usaha tidak dipengaruhi secara signifikan oleh kompetensi kewirausahaan. Hal ini menunjukkan bahwa kinerja usaha pada situasi pandemi Covid-19 dipengaruhi oleh faktor lain terutama pada kedai kopi skala mikro. Kinerja usaha kedai kopi skala kecil dipengaruhi lingkungan bisnis dengan koefisien jalur sebesar 0.542 .

\section{SARAN}

Perlu dikaji lebih lanjut faktor yang paling mempengaruhi kinerja usaha kedai kopi skala mikro pada situasi pandemi Covid-19.

\section{DAFTAR PUSTAKA}

Abdillah W, Hartono J. 2015. Partial Least Square $(P L S)$. Yogyakarta [ID]: Andi.

Aliyu MS. 2017. Entrepreneurial Competencies and the Performance of Small and Medium Enterprises (SMEs) in Zaria Local Government Area of Kaduna State. International Journal of Entrepreneurial Development, Education and Science Research (IJEDESR). 4(2):116-138.

Aulia MR. 2020. Pengaruh Kompetensi Kewirausahaan Terhadap Kinerja Usaha Kedai Kopi Skala Mikro dan Kecil di Kota Medan. Jurnal Manajemen Bisnis Krisnadwipayana (JMBK). 9(2):100-113.

Bergevoet RHM, Ondersteijin CJM, Saatkamp HW, Woerkum Van CMJ, Huirme RBM. 2004. Entrepreneurship Behavior pf Dutch Dairy Farmer Under Milk Quota System Goal, Objectives dan Attitudes. Wageningen (NL) : Elsevier. 80(2004): 1-21
Darya P. 2012. Pengaruh Ketidakpastian Lingkungan dan Karakteristik Kewirausahaan Terhadap Kompetensi Usaha dan Kinerja Usaha Mikro Kecil di Kota Balikpapan. Balikpapan. Jurnal Inovasi dan Kewirausahaan.

Glueck WF, Jauch LR. 1999. Manajemen Strategis dan Kebijakan Perusahaan. Jakarta : Erlangga. (Alih Bahasa Murad dan Henry Sitanggang)

Ghozali I, Latan H. 2015. Partial Least Square, Konsep, Teknik dan Aplikasi Menggunakan Program SmartPLS 3.0 Untuk Penelitian Empiris. Semarang: Badan Penerbit Universitas Diponegoro.

Hunger JD, Wheelen TL. 2007. Strategic Management and Business Policy. New Jersey: Prentice Hall Upper Saddle River.

Lackéus M. 2013. Developing Entrepreneurial Competencies: An Action-Based Approach and Classification in Entrepreneurial Education [Tesis]. Sweden (SE): Chalmers University of Technology.

Man TWY, Theresa L, KF Chan. 2002. The Competitiveness of Small and Medium Entreprises: A Conceptualization with focus on Entreprenurial Competencies. Journal of Business Venturing. 17(1): 123-142.

Moeheriono. 2009. Pengukuran Kinerja Berbasis Kompetensi. Jakarta (ID):Ghalia Indonesia.

Oyebanji J. 1994. Nigerian Business Environment and Organization Effectiveness. Nigeria : Abiola Booksho Limited.

Ozili PK, Arun T. 2020. Spillover of Covid-19: Impact on The Global Economy. Available at SSRN 3562570.

Radzi KM, Nor MNM, Ali SM. 2017. The Impact Of Internal Factors on Small Business Success: A Case of Small Enterprises Under The Felda Scheme. Asian Academy of Management Journal 22(1):27-55.

Rahman SA, Ahmad NH, Taghizadeh SH. 2016. Entrepreneurial Competencies of BoP Entrepreneurs in Bangladesh to Achieve Business Success. Journal of General Management. 42(1):45-63.

Tambunan T. 2009. Women Entrepreneurship in Asia Developing Countries: Their Development and Main Constraints. Journal of Development and Agricultural Economics. $1(2): 27-40$.

Tehseen, S., and Ramayah, T. 2015. Entrepreneurial Competencies and SMEs Business Success: The Contingent Role of External Integration. Mediterranean Journal of Social Sciences, MCSER Publishing, Rome-Italy. 6(1):50-61.

Pierce JA, Robinson RB. 1997. Manajemen Stretegic Formulasi Impelentasi dan Pengendalian. 
Jakarta : Binarupa aksara (Alih Bahasa Agus Maulana)

Wickham PA. 2004. Strategic Entrepreneurship. Essex (GB): Pearson Education Limited. (3).

Wilkinson B. 2002. Small, Micro, and Medium

Enterprise Development: Expanding the Options for Debt and Equity Finance. Financial Sector Workshop, National Economic Development and Labour Council (NEDLAC). 